\title{
Solution Suggesting Application Model to Minimize Delays and Cost Overrun for Low to Midrise Building Construction in Pampanga
}

\author{
Mark Gibson M. Pusod ${ }^{1, *}$, Bernard S. Villaverde ${ }^{2}$ \\ ${ }^{1}$ Graduate School, Mapua University, Intramuros, Manila, Philippines \\ ${ }^{2}$ School of Civil, Environmental, and Geological Engineering Associate Dean, Mapua University, Manila, Philippines
}

Received May 29, 2021; Revised August 23, 2021; Accepted September 21, 2021

\section{Cite This Paper in the following Citation Styles}

(a): [1] Mark Gibson M. Pusod, Bernard S. Villaverde, "Solution Suggesting Application Model to Minimize Delays and Cost Overrun for Low to Midrise Building Construction in Pampanga," Civil Engineering and Architecture, Vol. 9, No. 6, pp. 1920-1937, 2021. DOI: 10.13189/cea.2021.090623.

(b): Mark Gibson M. Pusod, Bernard S. Villaverde (2021). Solution Suggesting Application Model to Minimize Delays and Cost Overrun for Low to Midrise Building Construction in Pampanga. Civil Engineering and Architecture, 9(6), 1920-1937. DOI: 10.13189/cea.2021.090623.

Copyright $₫ 2021$ by authors, all rights reserved. Authors agree that this article remains permanently open access under the terms of the Creative Commons Attribution License 4.0 International License

\begin{abstract}
Given the growing economy in the Philippines, the exponential growth in the construction business in Pampanga creates jobs and boosts the industry. This research was conducted to examine various strategies or solutions to a specific construction problem and generates suggestions or effective ways to address them immediately. The system created in this study provides storage where the problem and solution can be documented for further studies and future use. The most frequent issues faced by construction companies that cause delays and expense overruns require a solid determination to take action. These problems are from construction studies and works of literature. A survey questionnaire was used to study the most suitable solution; the questionnaire includes standard answers to resolve the factors and minimize the cost that overruns the project. Field/site engineers, procurement officers, quality assurance engineers, and the project manager were the targets of this study. Cost overrun occurs because the elements were made naturally and by human. It was distinguished by mean factor examination utilizing Likert's scale and cross-organization utilizing Statistical Package for the Social Sciences Tools and algorithm utilizing Visual Studio Software (C-sharp program). The outcomes are the correlation of the elements between the two techniques, examination of the variables from the gathered information and the components gathered by
\end{abstract}

different engineers, and the arrangements experts made to reduce the impacts of these features.

Keywords Construction Cost, Cost Overruns, Mean Factor Analysis, Cross Tabulation, Construction Industry

\section{Introduction}

Fundamentally, a construction project is an effort with specified time \& cost, initiated to create a unique product, service, or outcome that tends to be limited edition. This project is a system that involves different operations designed to achieve a particular objective [1]. There are several things in construction that we need to think through to come up with a particular project, things like plans, records, resources, money, materials, machines, etc. Nevertheless, some factors make maintaining a plan on the scheduled path even more difficult [2].

Cost is a standout amongst the most essential factors in the consummation of a task. Cost overrun is known as the contrast between the genuine expense and the evaluated. Development cost overrun is experienced worldwide and was declined by the worldwide budgetary emergency brought about by contending the heightening of cost. Cost 
is one of the most important factors in the execution of a project. Cost overrun is known as the contrast between the genuine expense and the evaluated [1].

The number of construction development projects on the planet has increased, causing the global economy to fluctuate in tandem with the construction development business. Even though the lack of ability of individuals to finish extends on time and inside spending keeps an unending issue worldwide and is worsening. This issue has influenced the expense of loads of undertakings worldwide in various dimensions. Cost is a standout amongst the most vital factors in the culmination of a task. It is the most basic piece of any undertakings in development because, without the financial backing, no advancement will ever be made with the venture. However, it is surprising to many people that cost overrun is a common occurrence in development that affects countries all over the world, particularly those that are still developing, such as the Philippines [3]. According to Gould [4], efficient administration is critical to a productive and cost-effective facility. Due to insufficient planning and feasibility assessments, the scope of the project may alter. To effectively control the project, the project manager must adhere to the timetable in order to avoid excessive expenses and ensure that the building can be inhabited on time.

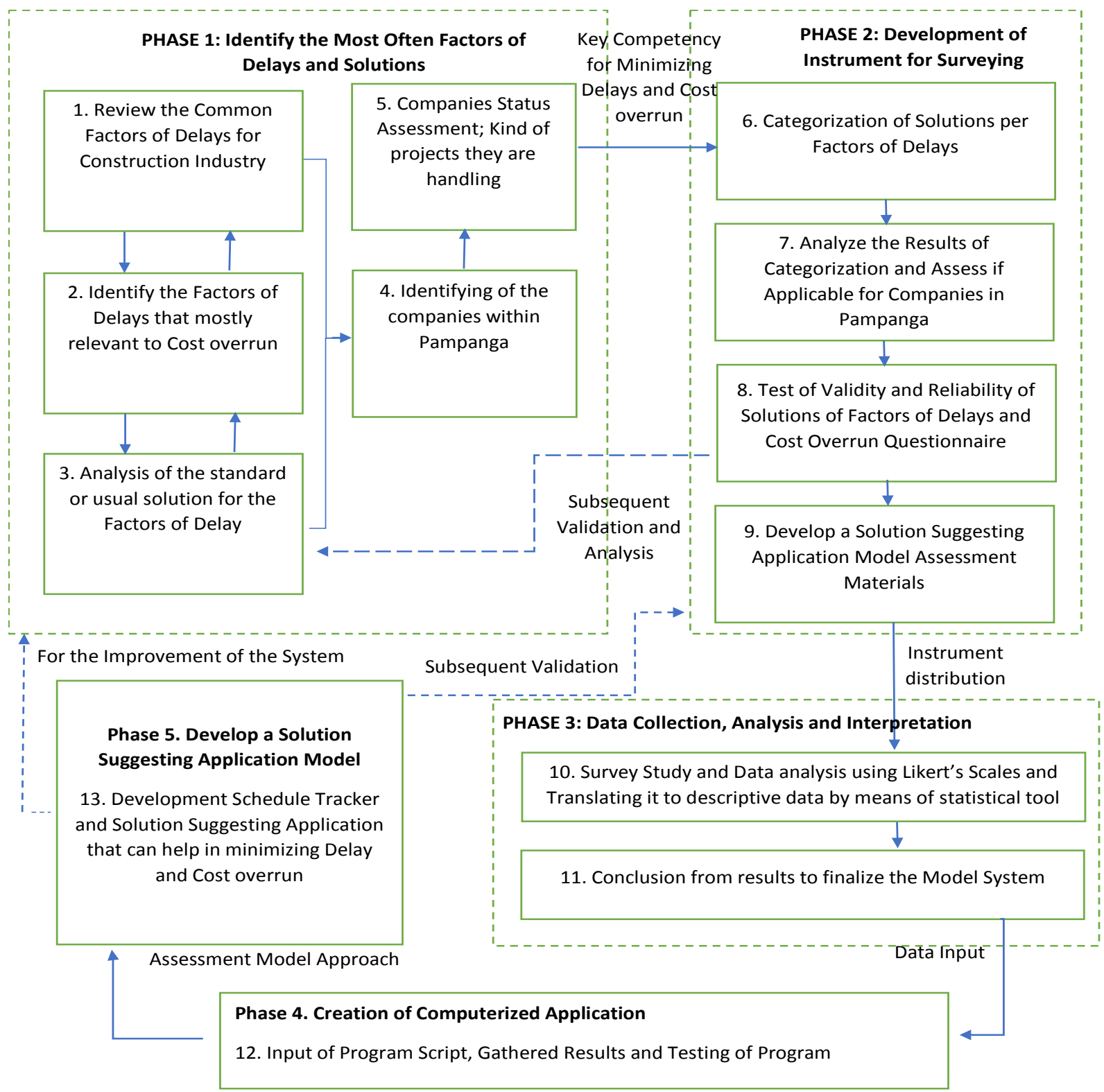

Figure 1. Conceptual Framework 
The main objective of this study is to develop a Construction Schedule tracker, Estimate versus Actual Construction Cost, and Solution Suggesting Application Model to minimize delay and cost overrun using a computerized program. This program will recognize the timeframe, budget costing of the project, and influencing factors that makes delays and suggest the best solutions to that problem. It additionally plans to give a thought on the best way to manage these sorts of issues within the development. A design support system can track construction schedule, estimate versus actual budget, and can give suggestions as a solution to the minimization of delays and cost overruns to mid-rise projects in Pampanga, Philippines.

\section{Conceptual Framework and Methodology}

This section will discuss the method and process of the Mean Factor analysis needed in this study. The formulation of the goal is to choose the best solution to suggest for the factors of delays and cost overrun and assigning of alternatives as well as of formulating survey questionnaire and validating the content of the questionnaire to be defined [5].

Factor Analysis (FA) is an exploratory procedure applied to a collection of observed variables that seeks to determine underlying factors (variables subsets) from which the observed variables are created. The comparison function of the observed variables is done [5]. A component is the initial variables weighted average. The factor analyst found enough variables that are used to produce the initial matrix of correlation.

As seen in figure 1 , the research was divided into five phases with thirteen stages in total. The researchers used this as a tool to accomplish the study's principal goal in this way. The steps are sequenced in such a way that the data and findings are not affected. The methodology section of the research is organized as follows.

\subsection{Phase 1: Identify the Most Often Factors of Delays and Solutions}

The review of literature and studies will be the basis of this study for the factors of delays and their common solutions. The study accumulated 13 factors of delays that lead to cost overrun.

Step 1: Review the common factors of delays for the construction industry.

Step 2: Identify the factors of delays and most relevant to cost overrun.

Step 3: Analyze the standard or usual solution for the factors of delays.

Step 4: Identifying the companies within Pampanga.
Step 5: Companies Status Assessment; Kind of projects they are handling.

13 Factors of Delays That lead to cost overrun from related literatures;

1. Short or scarcity of equipment, tools $[6,8]$.

2. Unreliable suppliers of materials on the local market $[7,8]$.

3. Strikes by site personnel $[8,9]$

4. Lack of human power and manpower skills $[7,8]$.

5. Payment delays to contractors and suppliers [10].

6. Rework required due to wrong or poor work or incorrect materials [11].

7. Change of work scope and complexity of work [12]

8. Poor communication of manpower and contractors $[13,14]$.

9. Poor monitoring, supervision and control[14,16]

10. Discrepancies and deficiencies in documents of the contract.[15]

11. Disputes among the parties involved in the project (clients, contractors, consultants) [16].

12. Poor Estimation of cost from bidding up to the cost of manpower and equipment [16].

13. Unexpected escalation of prices of materials used in construction [16].

\subsection{Phase 2: Development of Instrument for Surveying}

Step 6: Categorization of Solutions per Factors of Delays

Step 7: Analyze the Results of Categorization and Assess if Applicable for Companies in Pampanga

Step 8: Test of Validity and Reliability of Solutions of Factors of Delays and Cost Overrun Questionnaire

Step 9: Develop a Solution Suggesting Application Model Assessment Materials

\subsubsection{Survey-Questionnaire}

The questionnaire survey consists of 13 common factors in delays and cost overruns, also their most probable solutions during the construction phase. These factors were based on the results of previous researchers. The rating of the survey is based on a scale from very high to very low. This category helps in sorting out the most effective solution to the factors that cause delays and cost overruns. With these categories filled, we were able to identify the risk it gives to the construction project.

Quantitative surveys are designed to acquire information from individuals about themselves or about a social unit to which they belong or with which they are involved. In this study Thirteen (13) common cost overrun factors that were identified through a comprehensive examination of related literature was given to measure the effectiveness of the solution to a given factor in the construction industry. These are the common factors that were said to be present during construction process of the project. The efficacy of each factor in the best solution will be calculated based on findings of the study. 


\subsection{Phase 3: Data Collection, Analysis, and Interpretation}

Step 10: Survey Study and Data analysis using Likert's Scales and translating it to descriptive data utilizing the statistical tool

Step 11: Conclusion from results to finalize the Model System

\subsubsection{Data Collection}

A quantitative survey was used for this study to obtain the data required to conclude. It was done by written/online survey. It was decided based on the desires of the sample. Several companies were included to the possible members of the sample but they are still unsure because we still need to ask for their approval to be part of this research for future research about the construction industry of the Philippines.

The researcher used a survey form to gather information and data for this research report. This study includes thirteen (13) factors that trigger construction delays and cost overruns and nine solutions that respondents rated from highly effective to least or not effective. The queries were answered by the contractors, engineers, or other construction-related personnel who once worked or still operating in the construction of low to mid-rise buildings in Pampanga. The questionnaire was created using Google Form and the link from it was disseminated online. The analysis question survey is distributed through mail or social media and alike and answered using google form.

\subsubsection{Mean Score Analysis}

The average score of the solutions to the variables calculated as another method of determining the most successful solution to the common factor of cost overruns in Pampanga midrise projects. Table 1 serves as a reference of this analysis, and it is used as a variable in the mean score solution. The mean score was used to establish the importance and effectiveness of these solutions to the factors in mid-rise projects in Pampanga.

Likert's scale of five ordinal measures of the agreement was used to calculate the score of each factor.

Table 1. Relativity of the Scale to the Likert's Scale

\begin{tabular}{|c|c|}
\hline SCALE & LIKERT'S SCALE \\
\hline $0 \%-20 \%$ & 1 \\
\hline $21 \%-40 \%$ & 2 \\
\hline $41 \%-60 \%$ & 3 \\
\hline $61 \%-80 \%$ & 4 \\
\hline $81 \%-100 \%$ & 5 \\
\hline
\end{tabular}

Then, the Mean Score can be identified as follows (1).

$$
M S=\frac{\sum(\mathrm{F})(\mathrm{S})}{N}
$$

Where in:

MS = Mean Score

$\mathrm{F}=$ frequency of responses for each solution
$\mathrm{S}=$ Scores given by the respondents to each factors (From 1 to 5 ).

$\mathrm{N}=$ Total number of responses in the survey that concerns about the factor

\subsubsection{Scale of Ratings}

The impact of the solutions to the delay factors is determined through the rates of the sample. The rates will base on scales from Extremely Effective to Least (not) effective scales. Table 2 shows that the 1 to 1.9 is the Least or not Effective solution, 2.0 - 2.9 is slightly Effective, 3.0 - 3.9 is Moderately Effective, 4.0 - 4.9 is Very Effective and 5.0 is Extremely Effective. Extremely Effective, Very Effective, and Moderately effective will be considered to be the solution to a certain problem.

Table 2. Rate of the effectiveness of the Solution per Factor

\begin{tabular}{|c|c|}
\hline Scale & Equivalent Score \\
\hline Least (not) Effective & $1.0-1.9$ \\
\hline Slightly Effective & $2.0-2.9$ \\
\hline Moderately Effective & $3.0-3.9$ \\
\hline Very Effective & $4.0-4.9$ \\
\hline Extremely Effective & 5.0 \\
\hline
\end{tabular}

\subsection{Phase 4: Creation of Computerized Application}

Step 12: Input of Program Script, Gathered Results and Testing of Program

\subsubsection{Input of Program Script}

The software prototype will use Visual Studio Extended 2017 (VSE 2017) as a computer program. For a better understanding of how the prototype would be used and what it offers, a skeleton was developed. The data inputs are the expected and actual schedule of the project every week. Also, inputting the actual cost and estimated cost can be done to monitor if the value of the construction phase is over or underestimated. This data determines if the project is delay or in advance, and with a cost overrun or not. If delayed or underestimate, it will provide the top factors of cost overrun. After analyzing the reason for the delay, it will enumerate possible solutions to prevent or to overcome these delays.

The program was created to analyze and monitor projects with a maximum of 5floors only where their schedules created by the scheduler of the project must be stored in the project. The program can track the progress automatically basing on the schedule and the current date. It analyzes if the projects are on track or delayed. When the results show that the project is delayed, a suggesting box pops up to assist in making decisions in overcoming the deficits caused by cost overruns.

The definition of the system is established during the design stage. To begin this point, various software and tools were used. Visual Studio Extended 2017 (VSE 2017) 
was used to create a breathtaking look and feel across all platforms. Virtual Storage Extended is an operating environment for IBM mainframe computers. It's used to create whatever platform that the customer requires and wants to see.

The researcher used Visual Studio Enterprise 2017 as the code editor during the implementation stage of the framework. The DBMS (Database Management System) MySQL was used to save data inputs from users. MySQL is a SQL (Structured Query Language)-based interaction database management system. Data processing, e-commerce, and logging apps are only a few of the applications that use the software. MySQL, one of the most widely used database programs, is written in C\# and is used in many real-world 34 applications. Many institutions use this database, which is written in C\#.

\subsubsection{Gathered Data}

The survey-questionnaire distribution was done online with individuals or groups of practitioners who had worked in low to mid-rise buildings. It is done to gather data and opinions from professionals. The data was analyzed after all of the data was collected from all of the participants of the survey. The analysis is a tool that can help in ranking the factors gathered through the survey. The rankings of the study are determined based on their effectiveness. Analysis was done using the mean scores of the factor. It also identifies the solution to the most common factor based on which has the highest point on the sum of the mean scores for effectivity. The computer program was made with inputs from the progress of the project, the output will be from the results of the survey questionnaire.

\subsection{Phase 5. Develop a Solution Suggesting Application Model}

Step 13. Development Schedule Tracker and Solution Suggesting Application that can help in minimizing Delay and Cost overrun

The development of the Schedule tracker and Cost estimation with comparison to actual cost with the Solution Suggesting tool can help minimized Delay and Cost overrun. This application can store problems or factors that occurred on-site and solution that is not included in the default mode. The researcher created the software to be user-friendly and can be used by the client or non-engineering or technical staff. It is simple and can be executed by click and play.

\subsubsection{Instruction on how to use the Application}

1.) Turn on the XAMPP version 3.2.4 Control Panel.

2.) Click the Start button for Apache and MySQL as illustrated in figure 2.

3.) Figure 3 shows how to Open the Solution Suggesting Application.

There are three options.

a). Add New Project

b). Open Stored Project

c). Exit the application

XAMPP Control Panel v3.2.4 [ Compiled: Jun 5th 2019]

\begin{tabular}{|c|c|c|c|c|c|c|c|c|c|}
\hline ஆ & \multicolumn{4}{|c|}{ XAMPP Control Panel v3.2.4 } & & & & \multirow{2}{*}{$\begin{array}{l}\text { Config } \\
\text { Netstat }\end{array}$} & \\
\hline \multirow{6}{*}{$\begin{array}{l}\text { Modules } \\
\text { Service }\end{array}$} & Module & PID(s) & Port(s) & Actions & & & & & \\
\hline & Apache & $\begin{array}{c}20200 \\
9168\end{array}$ & 80,443 & Stop & Admin & Config & Logs & - Shell & \\
\hline & MySQL & 19404 & 3306 & Stop & Admin & Config & Logs & Explorer & \\
\hline & FileZilla & & & Start & Admin & Config & Logs & Services & \\
\hline & Mercury & & & Start & Admin & Config & Logs & (9) Help & \\
\hline & Tomcat & & & Start & Admin & Config & Logs & Q Quit & \\
\hline \multicolumn{2}{|c|}{$\begin{array}{l}\text { 9:50:19 AM [Apache] } \\
\text { 9:50:19 AM [mysql] } \\
\text { 9:50:20 AM [mysql] }\end{array}$} & $\begin{array}{l}\text { Status } \\
\text { Attem } \\
\text { Status }\end{array}$ & $\begin{array}{l}\text { etected: r } \\
\text { rt MySQL } \\
\text { etected: r }\end{array}$ & $\begin{array}{l}\text { nning } \\
\text { app... } \\
\text { nning }\end{array}$ & & & & & $\wedge$ \\
\hline
\end{tabular}

Figure 2. XAMPP version 3.2.4 Control Panel 


\section{$\uparrow$ NEW PROJECT}

Project Nam Mapua $\quad$ Start Date2020-12-0:

Activity Name Number of Week/s Estimated Cost Select Floor Number

Excavation

Back Fill

Foundation

Roof Beams

Roofing

Architectural Wo:s

Finishing Works :

Number of $\mathrm{F}^{*}$,rs:

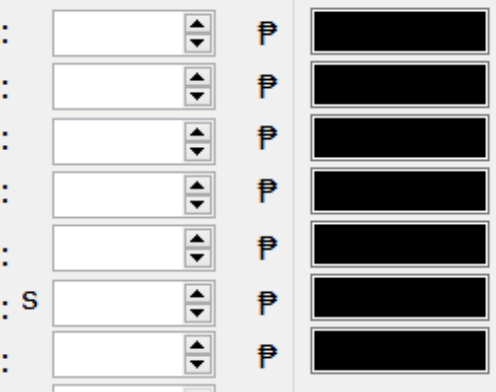

Figure 4. New Project Pop-up Menu of COST OVERRUN MINIMIZER APP

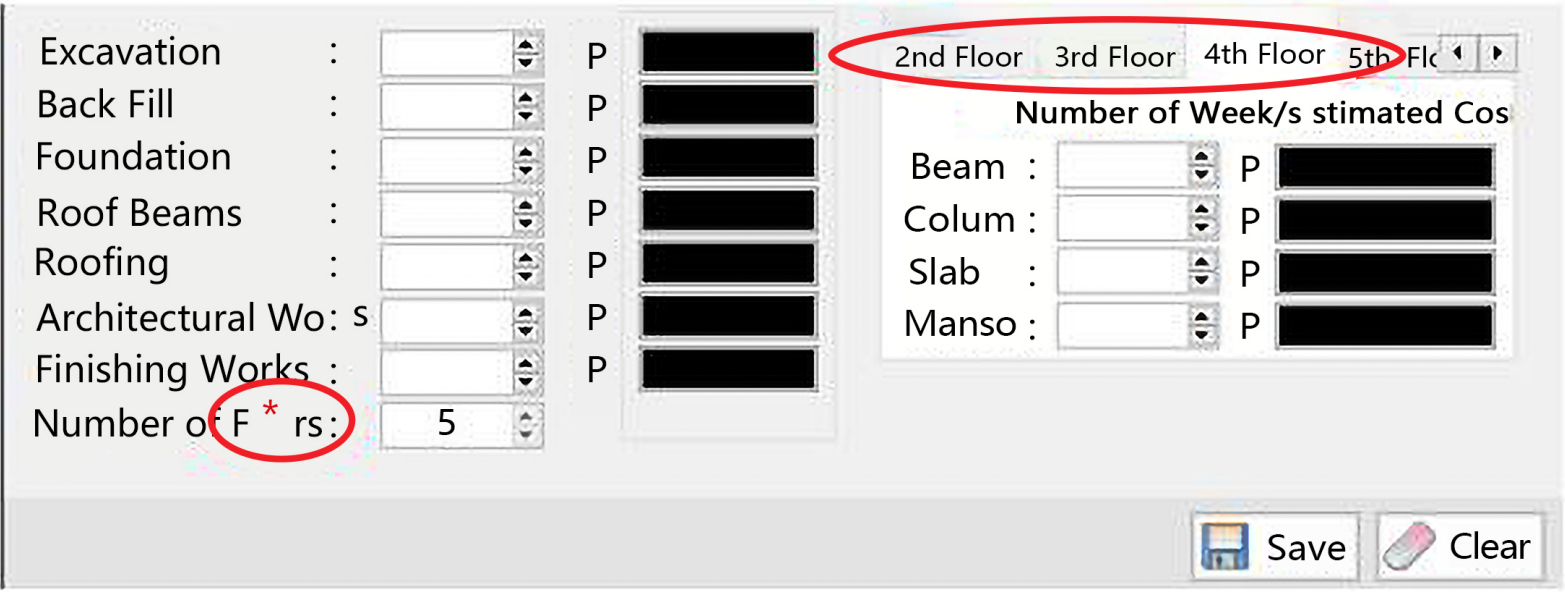

Figure 5. New Project Pop-up Menu of COST OVERRUN MINIMIZER APP

\subsubsection{Add New Project shown in Figure 4}

- On adding project the engineer or construction staff must fill the following information.

- $\quad$ Project Name - put the Name of the Owner, place or type of building at the space provided to easily identify the project.

- Start Date - choose the starting date of the construction project, the timeline of the project will be base here.

- $\quad$ Activity Name - the phase of the activity

- Number of Weeks - is the proposed schedule of the contractor to finish each phase of the construction.
- Estimated Cost - is the estimated cost per phase of the construction project.

- $\quad$ Select floor Number - will depend on how many floors the project has, referring to figure 5 .

- Save - to save your project in the Stored Project Button.

- $\quad$ Clear - will delete all the data inputted.

\subsubsection{Open Saved Project}

- Search and select the project that is stored see example in figure 6.

- Load the selected Project - figure 7 shows the condition of the project schedule and input the actual cost to differentiate it to eth estimated cost. 


\section{PROJECT LIST}

\section{Search Project Name :}

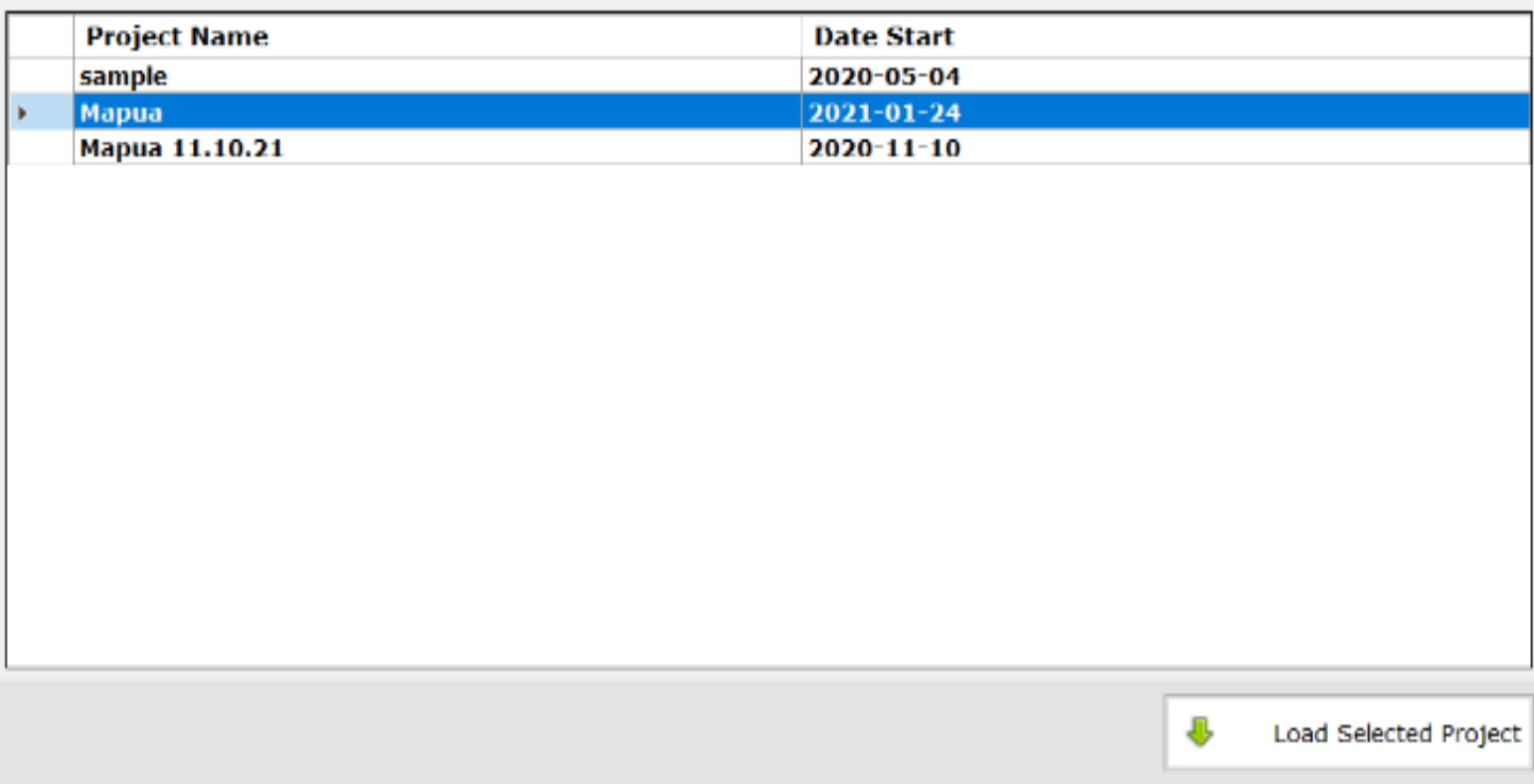

Figure 6. Project List Pop-up Menu of COST OVERRUN MINIMIZER APP

\begin{tabular}{|c|c|c|c|c|c|c|c|}
\hline \multicolumn{7}{|c|}{ O Mapua } & \\
\hline & Activity & Estimated Cost & Actual Cost & No of Weeks & End Date & Remarks & \multirow{2}{*}{$\begin{array}{l}\text { Activity Information } \\
\text { Activity Name }\end{array}$} \\
\hline & Excavation & 40000.00 & 20000.00 & 1 & $2021-01-31$ & Complete & \\
\hline & Backfill & 10000.00 & 40000.00 & 1 & $2021 \cdot 02 \cdot 07$ & Complete & Ground Foor Column \\
\hline & Foundation & 35000.00 & 32000.00 & 3 & $2021-02-28$ & Complete & Estimated Cost \\
\hline & Ground Floor Beam & 10000.00 & 11000.00 & 2 & $2021 \cdot 03-14$ & Complete & 63554.00 \\
\hline , & \begin{tabular}{|l|} 
Ground Floor Column \\
Ground Floor Stab \\
\end{tabular} & \begin{tabular}{|l|}
63554.00 \\
103333.00
\end{tabular} & $\begin{array}{l}100000.00 \\
0.00\end{array}$ & $\begin{array}{l}2 \\
1\end{array}$ & $2021-03-28$ & $\begin{array}{l}\text { Complete } \\
\text { Complete }\end{array}$ & Actual Cost \\
\hline & Ground floor Mansory & 35000.00 & 0.00 & 1 & 2021-04-11 & Complete & 100000.00 \\
\hline & 2nd Floor Beam & 50000.00 & 0.00 & 2 & 2021-04-25 & Complete & \multirow[b]{2}{*}{ Start Date : $2021-01-24$} \\
\hline & 2nd floor Column & 25000.00 & 0.00 & 2 & 2021-05-09 & In Progress & \\
\hline & 2nd Floor Slab & 54000.00 & 0.00 & 1 & $2021-05-16$ & Not Yet Started & \multirow[b]{2}{*}{ Number of Weeks : $\quad 2$} \\
\hline & 2nd Floor Mansory & 12300.00 & 0.00 & 1 & $2021-05-23$ & Not Yet Started & \\
\hline & Roof Beams & 40000.00 & 0.00 & 2 & 2021-06-06 & Not Yet Started & \multirow{4}{*}{$\begin{array}{l}\text { Edit } \\
\text { cost Analyze }\end{array}$} \\
\hline & Architectural Works & 100000.00 & 0.00 & 5 & $2021-07-11$ & Not Yet Started & \\
\hline & Finishing Works & 50000.00 & 0.00 & 5 & 2021-08-15 & Not Yet Started & \\
\hline & & & & & & & \\
\hline & & & & & & & \multirow{3}{*}{$\begin{array}{l}\text { Analyze Activity } \\
\text { Input Date : } 2021-04-28 \\
\text { Activity in Progress }\end{array}$} \\
\hline & & & & & & & \\
\hline & & & & & & & \\
\hline & & & & & & & Backfil \\
\hline & & & & & & & ACTIVITY Analyze \\
\hline
\end{tabular}

Figure 7. Project Menu Interface of COST OVERRUN MINIMIZER APP 


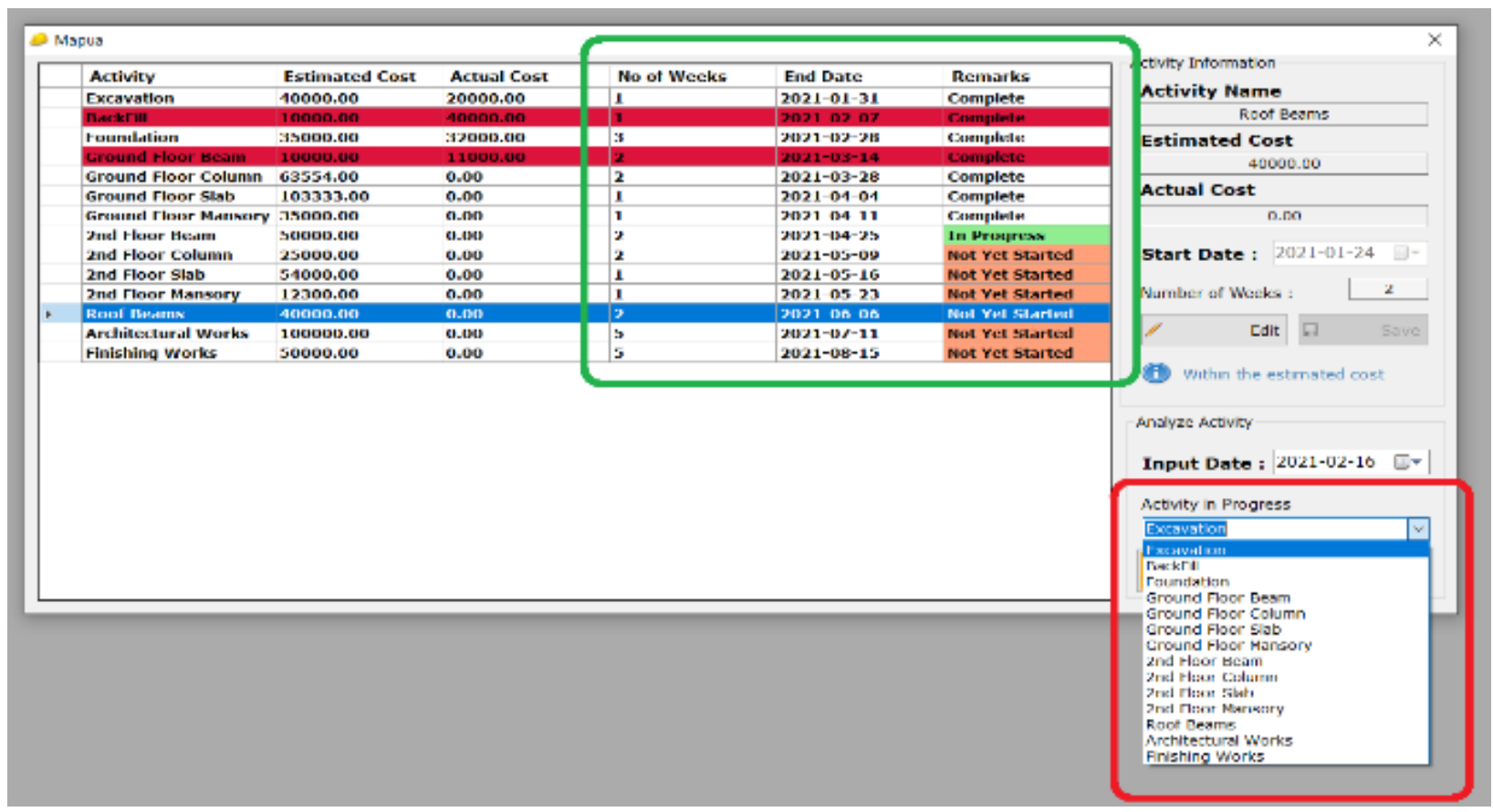

Figure 8. Project Menu Interface $>$ Activity in Progress

Input Date - if the computer's date or time is not updated.

To know if the activity is Ahead of time, On time or Delayed.

- Click "Activity Progress".

- $\quad$ Select the actual activity they are doing on site.

- Click "Analyze"

Figure 9 shows if the project is ahead of time the App will provide you the days and weeks prior to the schedule.

\begin{tabular}{|c|c|c|c|c|c|c|}
\hline & Activity & Estimated Cost & Actual Cost & No of Weeks & End Date & Remarks \\
\hline & Excavation & 40000.00 & 20000.00 & 1 & 2021-01-31 & Complete \\
\hline & Backfill & 10000.00 & 40000,00 & 1 & 2021-02:07 & Complete \\
\hline & Foundation & 35000.00 & 32000.00 & 3 & 2021-02-28 & Complete \\
\hline & Ground floor Beam & 10000.00 & 11000.00 & 2. & $2021-03-14$ & Complete \\
\hline & Ground floor Column & 63554.00 & 0.00 & & $2024-03-28$ & Complete \\
\hline & Ground Floor Slab & 103333.00 & 0.00 & Analyzed Result & 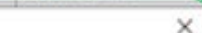 & Complete \\
\hline & Ground Floor Mansory & 35000.00 & 0.00 & Analyzea Kesuit & & Complete \\
\hline & 2nd floor Beam & 50000.00 & 0.00 & Ahead & & 10. Progress \\
\hline & 2nd Floor Column & 25000.00 & 0.00 & 6 woek's) and 6 dax & s) ahead on schedule & Not Yet Started \\
\hline & 2nd Floor Slab & 54000.00 & 0.00 & & & Not Yet Started \\
\hline & 2nd Floor Mansory & 12300.00 & 0.00 & Selected Activity: & Excavation & Not Yet Started \\
\hline , & Roof Beams & 40000.00 & 0.00 & Activity Based on Schedul & & Wot Yet Started \\
\hline & Architectural Works & 100000.00 & 0.00 & & & Not Yet Started \\
\hline & Finishing Works & 50000.00 & 0.00 & Input Date : & $2020-12-14$ & Not Yet Started \\
\hline & & & & Activity Based on Input D & & \\
\hline
\end{tabular}

\begin{tabular}{l} 
Activey Information \\
Activity Name \\
Roof Beams \\
Estimated Cost \\
\hline 40000.00 \\
\hline Actual Cost \\
\hline Start Date : $2021-01-24$ \\
Number of Weeks : \\
Edit \\
(1) Within the estimated cost \\
Analyze Activity \\
Input Date : $2020-12-14$ \\
Activity in Progress \\
\hline Excavation \\
\hline af ACTIVITY Analyze \\
\hline
\end{tabular}

Figure 9. Project Menu Interface > Analyzed Result "Ahead”

Figure 10 shows if the project is tracking On time the App will give a notice that it is "In Progress". 


\begin{tabular}{|c|c|c|c|c|c|c|}
\hline & Activity & Estimated Cost & Actual Cost & No of Weeks & End Date & Remarks \\
\hline & Excavation & 40000.00 & 20000.00 & 1 & 2021-01-31 & Complete \\
\hline & Backfill & 10000.00 & 40000.00 & 1 & 2021-02-07 & Complete \\
\hline & Foundation & 35000.00 & 32000.00 & 3 & 2021-02-28 & Complete \\
\hline & Ground floor Beam & 10000.00 & 11000.00 & 2 & 2021-03-14 & Complete \\
\hline & Ground Floor Column & 63554.00 & 0.00 & ? & $2021-03-28$ & Complete \\
\hline & Ground Floor Slab & 103333.00 & 0.00 & \multirow{2}{*}{ Analyzed Result } & \multirow{2}{*}{$\times$} & Complete \\
\hline & Ground Floor Mansory & 35000.00 & 0.00 & & & Complete \\
\hline & 2nd Floor Beam & 50000.00 & 0.00 & \multirow{2}{*}{ (1) In Pr } & & In Progress \\
\hline & 2nd Floor Column & 25000.00 & 0.00 & & (s) remaining before end & ot Yet Started \\
\hline & 2nd Floor Slab & 54000.00 & 0.00 & \multirow{2}{*}{ Selected Activity : } & & l ot Yet Started \\
\hline & 2nd Floor Mansory & 12300.00 & 0.00 & & Excavation & ot Yet Started \\
\hline \multirow[t]{4}{*}{, } & Roof Beams & 40000.00 & 0.00 & \multicolumn{2}{|c|}{ Activity Based on Schedule Excavation } & ot Yet Started \\
\hline & Architectural Works & 100000.00 & 0.00 & \multirow{2}{*}{\multicolumn{2}{|c|}{ Input Date : $\quad 2021-01-27$}} & ot Yet Started \\
\hline & Finishing Works & 50000.00 & 0.00 & & & 1 ot Yet Started \\
\hline & & & & \multicolumn{2}{|c|}{ Activity Based on Input Date : vation } & \\
\hline
\end{tabular}

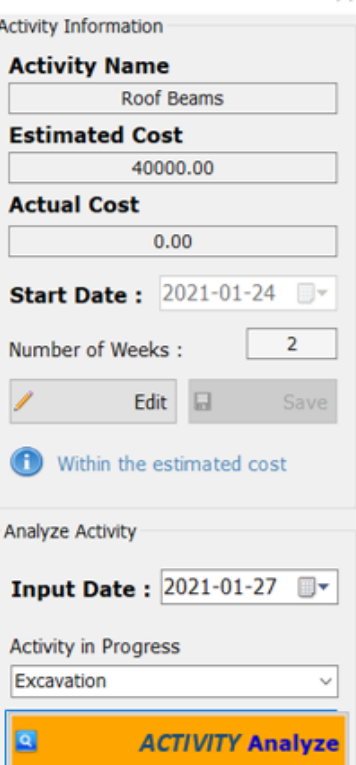

Figure 10. Project Menu Interface > Analyzed Result “In Progress”

Figure 11 shows if the project is delayed the App will give notice that it is "Delayed".

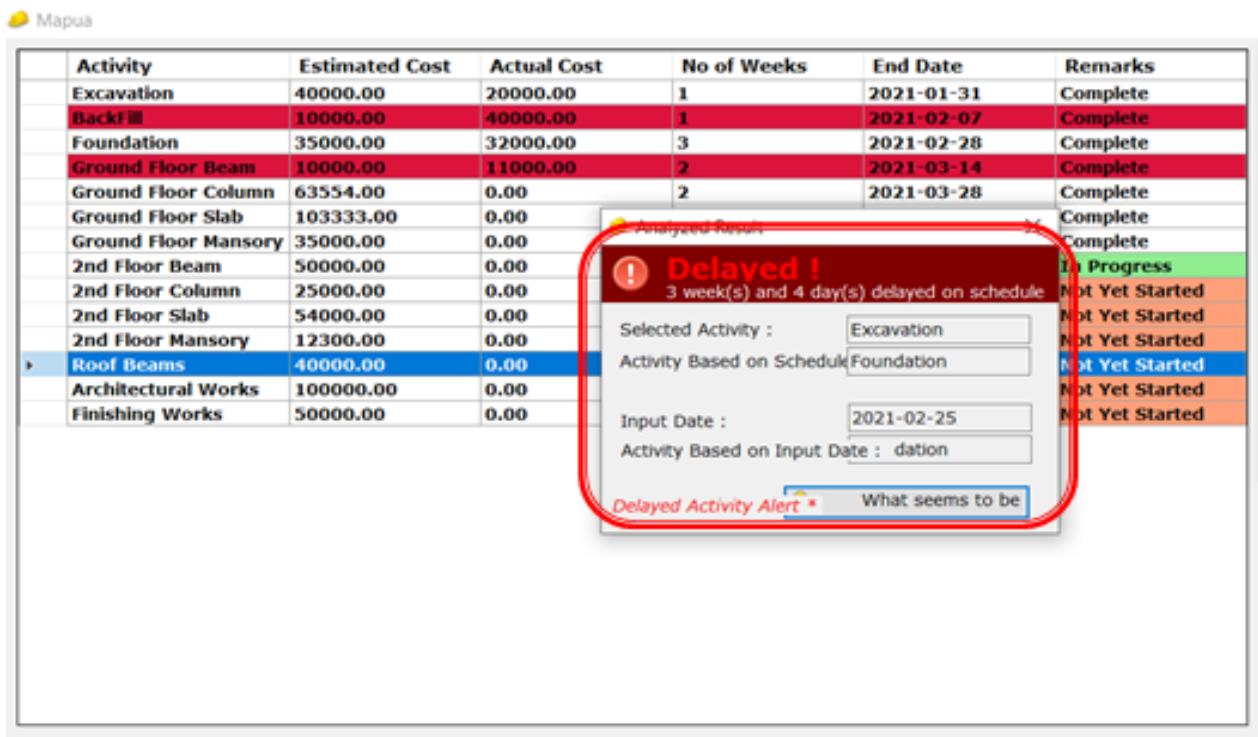

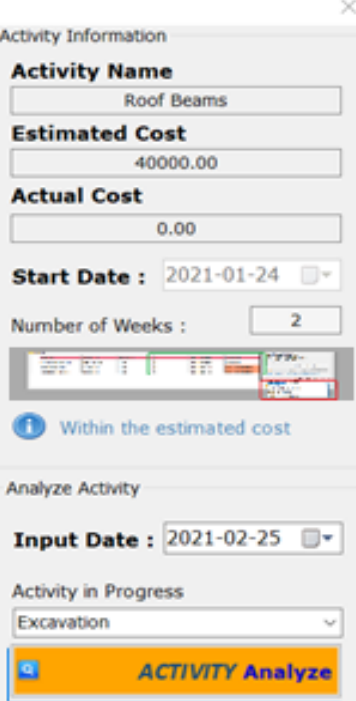

Figure 11. Project Menu Interface > Analyzed Result "Delayed!"

Delayed Tab

If the project is Delayed click the "What seems to be the Problem" button to help you to find out the problem see figure 12. 


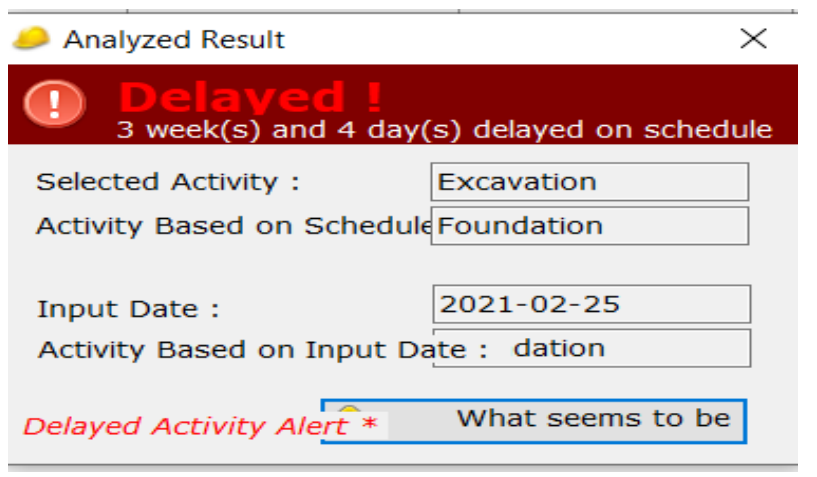

Figure 12. Pop-up Notice Window of COST OVERRUN MINIMIZER APP

Figure 13 shows the following interface of the application.

- Problem Solution Window will pop-up to choose what problem is the cause of delay.

- The Most effective Possible Solution is ranked based on the data gathered.

- $\quad$ Suggested Solution Tab is also provided if there are Solutions that can be done in that specific problem.

- Adding and Deleting Possible Problem, Possible Solution and Suggestion Solution is also allowed.

- $\quad$ Printing can be done by clicking File $>$ Print.

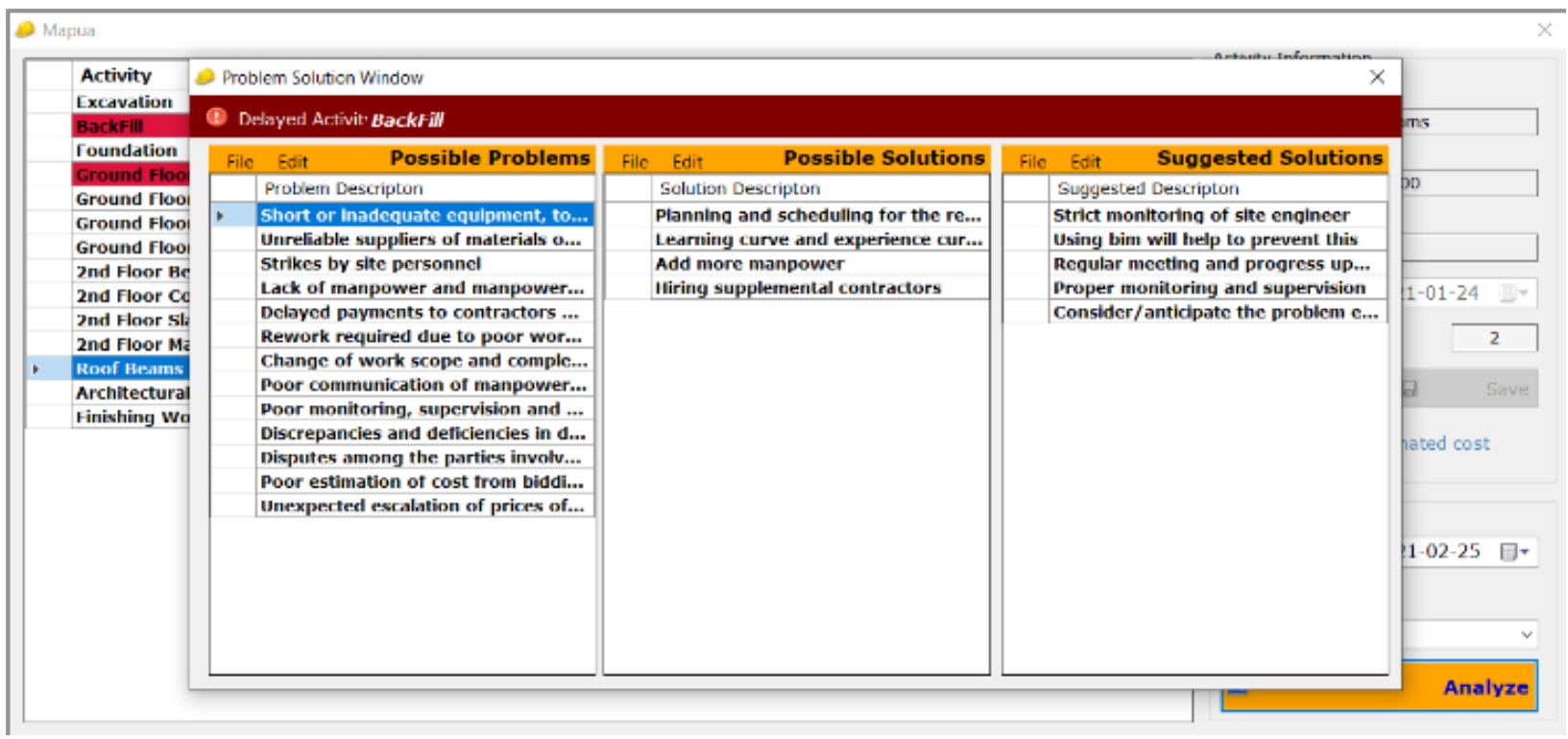

Figure 13. Problem Solution Window of COST OVERRUN MINIMIZER APP

\subsection{Statement of the Problem}

The main objective of this study is to develop a Construction Schedule tracker and Solution Suggesting Application Model to minimize delay and cost overrun using a computerized program. This program will recognize the timeframe of the project and influencing factors that make delays and suggest the best solutions to that problem. It additionally plans to give a thought on the best way to manage these sorts of issues within the development.

Specifically, the study will mainly address the following:

1. Identify the factors in delay or cost overrun and their solutions and the activity of the significant players in the development of the construction business in Pampanga.

2. Analyze which factor needs the most consideration from the significant players of the construction industry.

3. Evaluate the effectiveness of the solutions for the factors of delays and cost overruns, distinguished by mean factor examination utilizing Likert's scale and cross-organization utilizing Statistical Package for the Social Sciences Tools.

4. Synthesize a computer application program and algorithm using Visual Studio Software (C-sharp program), inputting data from the assessment tool.

5. Develop a design support system that can track construction schedules and can give suggestions as a 
solution to the minimization of delays and cost overruns to mid-rise projects in Pampanga.

\subsection{Research Design}

This chapter explains how to classify the factors that influence construction delays and their effect on cost overruns using a technique.

The research is Quantitative Research as it aims to develop and create or design a computer support system to help construction companies to build ideas on how to solve the common problem related to construction delays.

The research will focuse on the region of Pampanga mainly in Angeles City and Clark area for the development in these areas are fast and large. The respondents of the study will be mainly composed of the contracting companies that are having ongoing projects in Pampanga Area.

The methodology has five Phases. Phase I focuses on the common factors of delays utilizing related literature and related studies. Phase II will be the design of the research instrument. Phase III is the analysis of the best solution for delays that may lead to cost overrun. Phase IV, synthesizing of the computer supporting system to input the data gathered and the last phase. Phase V is the function of the construction schedule tracker and suggesting the best solution to a certain problem to minimize delays and cost overrun.

The study is categorized as Quantitative Research and Explanatory Research. Quantitative surveys are designed to acquire information from individuals about themselves or about a social unit to which they belong or with which they are involved, Larsen et al. [17]. Quantitative survey are created to obtain information about themselves or about a societal unit to which they are included or which they are involved. To measure the effectiveness of the solution to the factors of cost overburden that will encounter in the project. 13 common cost overrun or delaying factors were defined through a thorough review of related literature. These factors are common factors that were said to be experiencing during the construction phase of the project. Since quantitative research is used to populate statistics to gain statistically valid results in customer/professionals/respondents' insight where it is incorporated as a survey-based approach to gain feedback about a population's ideas and opinions. The focus of the study is on analyzing and determining the cost overrun factors in the one to five-story building construction projects in Pampanga. The factors and triggers included in this analysis are those that arise during the construction process and any unforeseen incidents. The compiled cost overrun and delaying factors are based on reviews of related literature and personal knowledge based on the news and experience of other professionals. The study was designed as quantitative analysis, with professionals filling out a questionnaire for surveys and interviews, and data was then analyzed using the Mean Factor Analysis method in SPSS.

\section{Analysis of Results}

\subsection{Demographic Information of the Respondents}

\subsubsection{Gender}

Figure 14 displays the number of genders, male and female respondents in the survey. The percentage for men is $80 \%$ represented by the blue color. For the women, it is represented by the red color composing of $20 \%$. There were 24 men and 6 women among the survey respondents. The researcher did not predetermine the male-to-female ratio; instead, the sample questionnaires were administered at random.

\subsubsection{Years of Experience}

Figure 15 depicts the respondents' percentages of years spent in constructing building. The respondents who have worked in construction for three to four years account for the highest proportion of $40 \%$. Five years and more was the second highest proportion at $36.7 \%$. With a rate of $23.3 \%$, fresh graduates to two years of construction experience have the lowest percentage of years of experience. The survey respondents were composed of 7 with $0-2$ years of construction experience, 12 with 3-4 years, and 11 with 5 years and above experience in the industry. 


\section{Gender}

30 responses

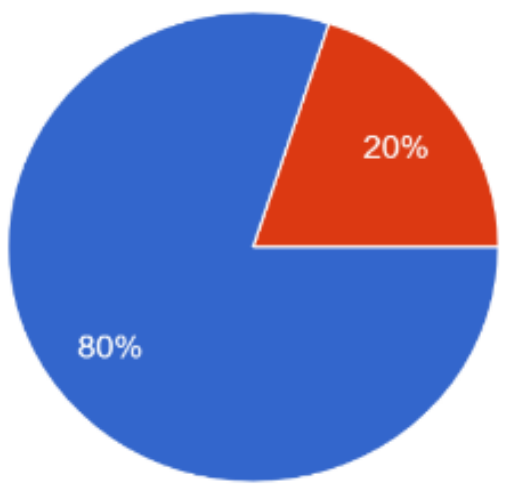

Male

Female

Figure 14. Pie Chart Showing Percentage of Gender of the Respondents

\section{Years of Experience in Civil Engineering Field}

\section{0 responses}

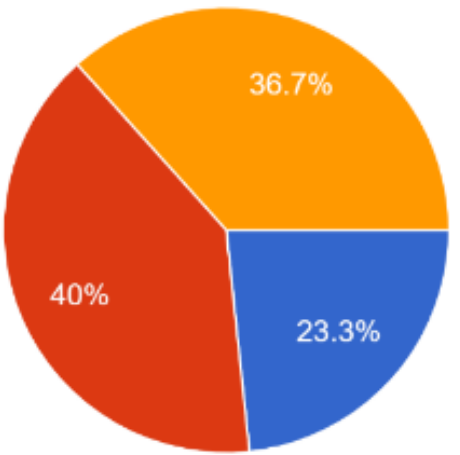

5 years and above

Figure 15. Pie Chart Showing Percentages of the Respondents' Years of Experience

\section{Position}

30 responses

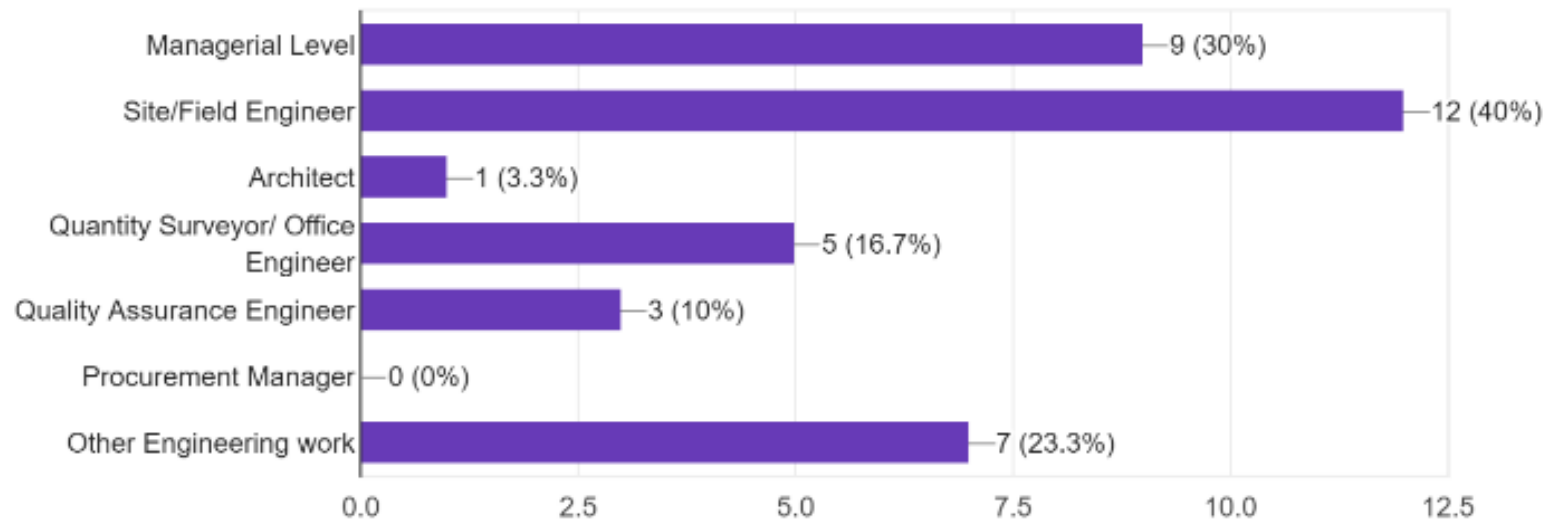

Figure 16. Bar Chart Showing Percentages of the Respondents' Position in the Company 


\subsubsection{Position or Line of Work}

Figure 16 illustrates the position in the company or the line of work of the respondents and it shows that Site/field Engineers were $40 \%$, Managerial Level was 30\%, Other engineering works were 23.3\%, Quantity Surveyor/Office Engineers were 16.7\%, Quality Assurance Engineers were $10 \%$ and $3.3 \%$ of architects responded.

\subsubsection{Location of Construction Site}

Figure 17 shows the Project Location (City/Municipality in Pampanga) of the Respondents. There were 22 Municipalities to complete the Province of Pampanga in the Philippines. The highest percentage of having a residential project was in Angeles City having $40 \%$. The second highest was in Mabalacat with 26.7\%. The third was in the City of San Fernando with $20 \%$, followed by the Lubao with $16.7 \%$. The fifth Project Location was in Florida Blanca and Magalang with 10\%. Bacolor, Guagua,
Mexico, Minalin and Santo Tomas were 6.7\%. Macabebe was $3.3 \%$ of the respondents.

\subsection{Survey Results for the Mean Score of the Solution per Factor}

The mean score of the solutions for the factors was determined as another way of the analysis of the most effective solution to the common factor in cost overruns in mid-rise projects in Pampanga.

\subsubsection{Factor 1: Short or inadequate equipment or tool}

The First Factor in Cost overrun and Delay is "Short or inadequate equipment or tool". The most effective were Planning and Scheduling for the rest of the project frequently, and Learning curve and experience curve that has mean score of 4.07, Add more manpower was 3.57, and Hiring Supplemental contractors was 3.13.

\section{Project Location (City/Municipality in Pampanga) \\ 30 responses}

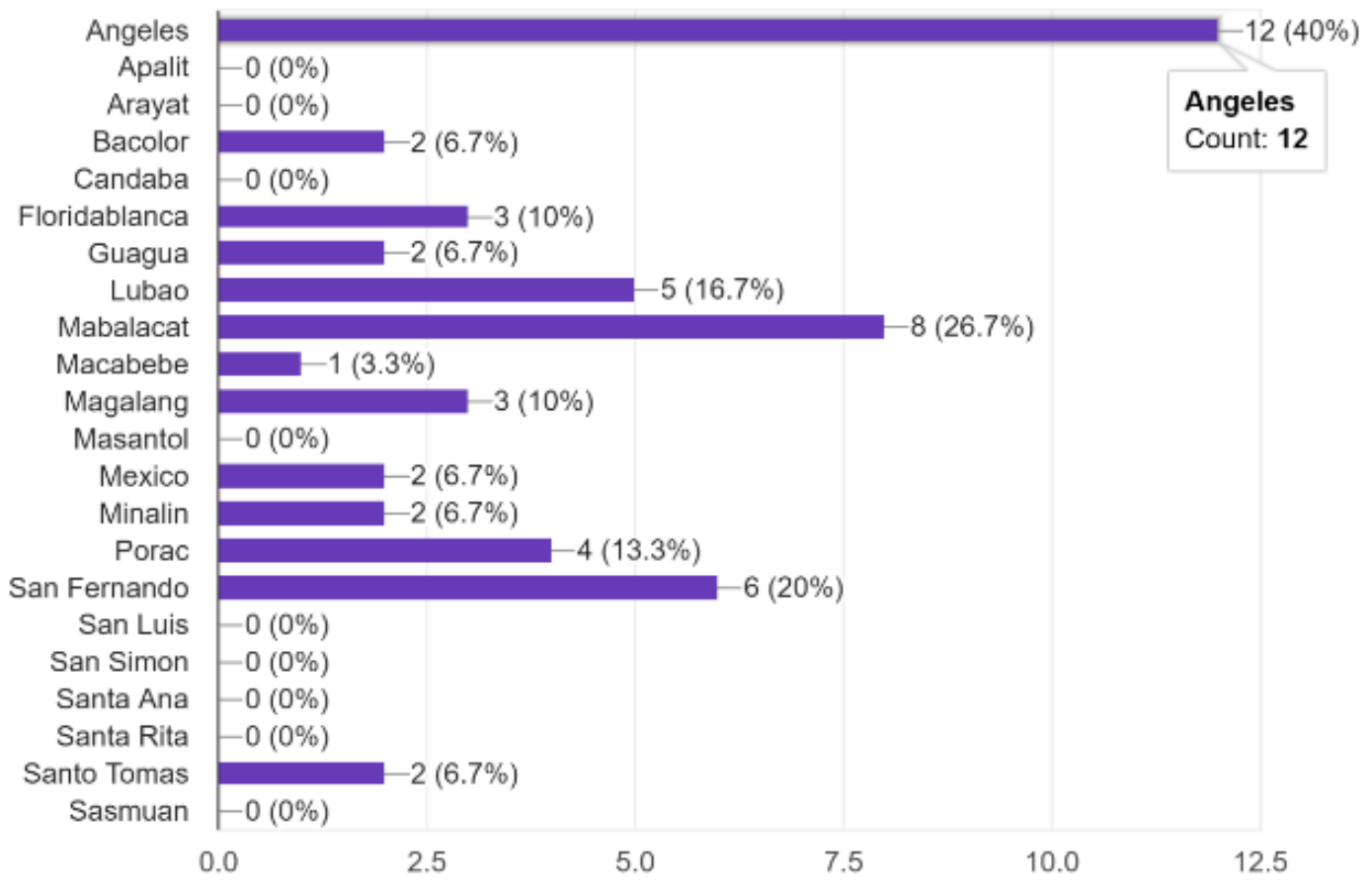

Figure 17. Bar Chart Showing Percentages of the Respondents' Project Location 
Other suggestion respondents recommended are as follows;

- $\quad$ Strict monitoring of site engineer

- Planning ahead is key. Some delays may be inevitable if missed from planning stage. If it's already there, adding burden to the exhausted man power isn't going to help. Our people should be first, their safety and well-being should be our top priority. Minimizing delays and costs will always depend on the situation. No one size fits all for all sites are individually unique. Using BIM will help to prevent this. Regular meeting and progress updates are necessary to deal with present delays and lay down applicable and accurate solutions to problems. Coordination of all teams is a beacon for this. Communication is gold.

- Proper monitoring and supervision

- Prepare construction schedule in a scientific way to avoid problems. Consider/anticipate the problem earlier and strictly follow the prepared const. schedule.

\subsubsection{Factor 2: Unreliable Suppliers of materials on the Local Market}

The Second Factor in Cost overrun and Delay is "Unreliable Suppliers of materials on the Local Market". The most effective were Planning and Scheduling for the rest of the project frequently which has a mean score of 3.80, Learning curve and experience curve that has a mean score of 3.60, and Hiring Supplemental contractors were 3.13.

Other suggestion respondents recommended are as follows;

- $\quad$ Purchase supplies on near province

- Contracts are very important when it comes to suppliers. Terms and conditions must be double checked. Scout for suppliers who are known for their honor and integrity.

\section{- $\quad$ Provide contract}

\subsubsection{Factor 3: Strikes by Site Personnel}

The Third Factor in Cost overrun and Delay is "Strikes by Site Personnel". The most effective were Planning and Scheduling for the rest of the project frequently that has a mean score of 3.97, Learning curve and experience curve that has mean score of 3.43, Replace Manpower 3.10 and Hiring Supplemental contractors was 3.00.

Other suggestion respondent's recommended are the following;

- Leadership present on site will impact greatly the team. If leader is not a person of integrity you cannot expect responsible execution from his members.

- $\quad$ Frequent tool box meeting to address demands.

\subsubsection{Factor 4: Lack of Manpower Skills}

The Forth Factor in Cost overrun and Delay is "Lack of
Manpower Skills”. The most effective was the Learning curve and experience curve that has a mean score of 3.93, Planning and Scheduling for the rest of the project frequently that has to mean score of 3.90, Add Manpower has 3.67, Hiring Supplemental contractors was 3.27, and Replace Manpower 3.10.

Other suggestion respondents recommended are as follows;

- Consider Skill/trade testing as part of the pre-employment requirement.

- Consider planning of manpower utilizations.

\subsubsection{Factor 5: Delayed Payment of Contractor and Supplier}

The Fifth Factor in Cost overrun and Delay is "Delayed Payment of Contractor". The most effective were Planning and Scheduling for the rest of the project frequently which has a mean score of 3.60 and the Learning curve and experience curve that has a mean score of 3.13 .

Other suggestion respondents recommended are as follows;

- Add collateral damages fee

\subsubsection{Factor 6: Rework required due to poor work or} incorrect materials

The Sixth Factor in Cost overrun and Delay is "Rework required due to poor work or incorrect materials". The most effective were Planning and Scheduling for the rest of the project frequently has a mean score of 3.70, and Learning curve, experience curve that has a mean score of 3.63, and Replaces Manpower 3.60.

Other suggestion respondents recommended are as follows;

- Skilled/trade testing to acquire more qualified workers.

- Monitor the project weekly and always check the materials needed

- Close monitoring of project is necessary in this situation

\subsubsection{Factor 7: Change of Work Scope and Complexity of} Work

The Seventh Factor in Cost overrun and Delay is "Change of Work Scope and Complexity of Work". The most effective were Planning and Scheduling for the rest of the project frequently has a mean score of 3.97, Learning curve and experience curve has a mean score of 3.87, Extend Project Duration 3.40, and Add Manpower 3.30.

\subsubsection{Factor 8: Poor Communication of Manpower and Contractor}

The Eighth Factor in Cost overrun and Delay is "Poor Communication of Manpower and Contractor”. The most effective was Planning and Scheduling for the rest of the project frequently has a mean score of 3.80 , and the Learning curve, experience curve has a mean score of 3.57. 
Other suggestion respondents recommended are as follows;

- $\quad$ Assign a project coordinator.

\subsubsection{Factor 9: Poor Monitoring, Supervision and Control}

The Ninth Factor in Cost overrun and Delay is "Poor Monitoring, Supervision and Control”. The most effective was the Learning curve, the experience curve has a mean score of 3.97, and Planning and Scheduling for the rest of the project frequently has a mean score of 3.83.

Other suggestion respondents recommended are as follows;

- Conduct trainings to improve the supervision

- Schedule a weekly project progress meeting to closely monitor the condition of site.

\subsubsection{Factor 10: Discrepancies and Deficiencies in Documents of the Contract}

The Tenth Factor in Cost overrun and Delay is "Discrepancies and Deficiencies in Documents of the Contract”. The most effective were Planning and Scheduling for the rest of the project frequently has a mean score of 3.93, and Learning curve, experience curve that has a mean score of 3 .

Other suggestion respondents recommended are as follows;

- Always Review the contract agreement/(TOR) terms of reference with the proponent.

- Review your documents ahead of time

- Make checklist.

\subsubsection{Factor 11: Dispute among the Parties (Clients,} Contractors and Consultants)

The Eleventh Factor in Cost overrun and Delay is "Dispute among the Parties (Clients, Contractors, and Consultants)". The most effective were Planning and Scheduling for the rest of the project frequently has a mean score of 3.73 and Learning curve, experience curve has a mean score of 3.37 .

Other suggestion respondents recommended are as follows;

- A weekly coordination meeting is enough. From the every will be aware of site condition and/or if there were any suggestions/concerns/problems of any involve individual in the project. That could possibly address or resolve immediately.

3.2.12. Factor 12: Poor Estimation of Cost from Bidding up to the Cost of Manpower and Equipment

The Twelfth Factor in Cost overrun and Delay is "Poor
Estimation of Cost from Bidding up to the Cost of Manpower and Equipment”. The most effective were Planning and Scheduling for the rest of the project frequently has a mean score of 3.83, and Learning curve, experience curve has a mean score of 3.80 .

Other suggestion respondents recommended are as follows;

- $\quad$ Review properly the terms of reference.

\subsubsection{Factor 13: Unexpected Escalation of Prices of} Materials used in Construction

The Thirteenth Factor in Cost overrun and Delay is "Unexpected Escalation of Prices of Materials used in Construction". The most effective were Planning and Scheduling for the rest of the project frequently has a mean score of 3.73 and Learning curve, experience curve has a mean score of 3.13 .

Other suggestion respondents recommended are as follows;

- $\quad$ Request for additional cost

- $\quad$ Proposed a Variation order.

- $\quad$ Add margin of error

\subsection{Testing Results of Computer Application}

After the findings of the common factors of delays and outcome of the survey questionnaires for the most effective solutions, inputting of gathered data to the application is required (See Phase 2.5 for instructions). Shown in figure 18 is the Framework on how the application will work. It outlines the procedures that need to be taken and implement the process that provides a new in construction projects, based on the common factors and solutions.

Testing is done in the last stage to develop the cost overrun minimizer app. In the testing process, a test run is done on Windows 10 Pro x64. This was made to check if the functionalities of the system are working; another is to check for bugs to fix and make sure that the system runs on both Windows 7 and Windows 10 as it should. To run the system, it needs some requirements and applications in the user's computer or laptops such as (1) Windows 10 version 1507 or higher: Home, Professional, Enterprise (2) 1.8 $\mathrm{GHz}$ or faster processor (3) 4GB RAM or higher (4) .Net Framework 4.5.2 or above is required: latest .Net Frameworks (5) XAMPP version 3.2.4.

The application can monitor the budget and the schedule based on the data entered by the user. If there are any delays or cost overruns between estimated and actual value, the application will provide a notice (see figure $11 \& 12$ ) and give the details of the losses in terms of time or money. 


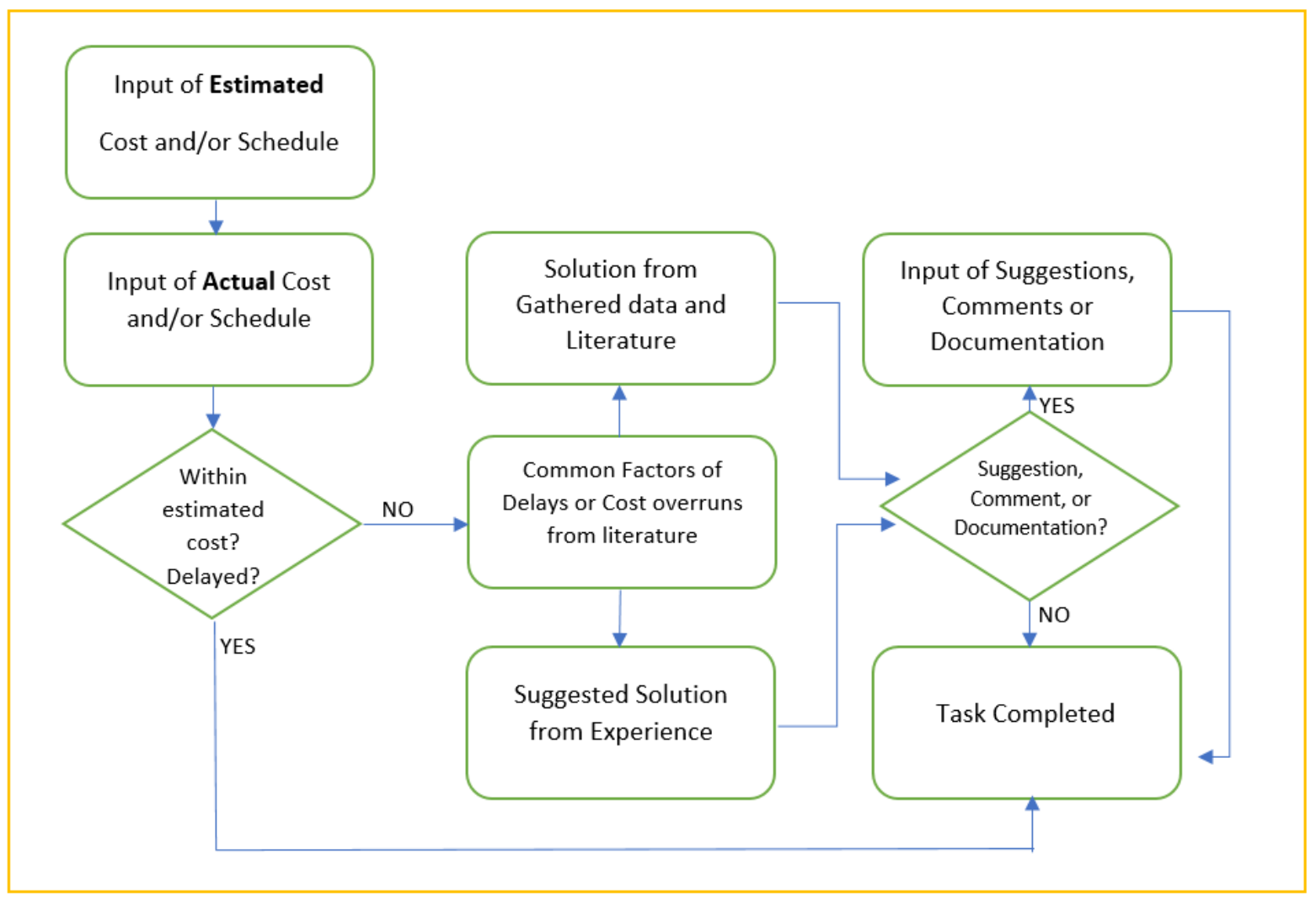

Figure 18. Framework of Computer Application

\section{Discussion and Conclusion}

The artificial intelligence of suggestion and decision-supporting system can help in minimizing the factors in cost overruns. This computer application can assist or propose a solution to a common workplace issue to construction companies, engineers or clients.

Crucial decision-making has a substantial impact on the construction project time, budget, and quality level [17]. On construction projects, delays are the most prevalent and expensive issue. Construction delay analysis has become an important aspect of the project's life cycle. Schedule documentation establishing liability prepares for litigation. Preparing such schedules can be time-consuming and costly with current project tracking tools. The analysis is frequently complicated, and automated technology can help [19]. The introduction of a computer system that helps in delaying factors is described in this work. Information technology is a process whose advancement is based on three factors: first, people's deepening understanding of their business activities; second, the development of information technology, such as computing technology, network technology, artificial intelligence, and so on; and third, IT penetration and transformation capabilities. The primary goal of enterprise information is to improve the competitiveness of businesses by optimizing their business activities to make them more effective [20].

The outcomes of this study reveal that the most effective solution for all the factors or problems presented in this paper is frequently planning and scheduling for the rest of the project, and doing a learning curve and experience curve. Other potential solutions for these factors can be incorporate, and these solutions can be found in related literature or study, and recommended explanations. The construction project problems are also influenced by the construction staff's experience or the common familiarity of other construction engineers.

With these results, the researcher created a computer application system that can give a solution to these factors. The software includes the mean scores of the outcomes that are above or near the moderate ranking for effectiveness boundaries. The problems in the construction process are to be anticipated, but resolving them quickly saves money, time, and effort.

Visual Studio Extended 2017 (VSE 2017) was the programming software used in this computer-aided application. The data inputs are the project's planned and actual schedules for each week. Inputting the real and projected costs can also be done to see if the value of the construction phase is overestimated or underestimated. This information decides whether the project is behind schedule or ahead of schedule, and whether or not there is a cost overrun. It will provide the top factors of cost overrun 
if it is delayed or underestimated. It will enumerate potential solutions to avoid or resolve delays after evaluating the cause of the delay.

The application was designed to evaluate and track projects with a maximum of 5 floors and schedules generated by the project's scheduler that must be saved throughout the project. Based on the schedule and the current date, the program will monitor the progress automatically. It determines whether the projects are on schedule or behind schedule. When the results indicate that the project is behind schedule, a suggestion box appears to help you make decisions on how to avoid the deficits generated by cost overruns. This application can be used to document any difficulties that occurred on-site that were not covered by the common factors. It could be a database of factors and solutions that can be used in the future.

In terms of future research, studies like these may be expanded, which would provide useful insight into how new concepts and approaches are implemented and perfected. This should prove to be a useful tool for understanding the relationship between advanced technological research and actual applications in the construction industry. Similarly, new approaches and theories are incorporated into the development process.

\section{Acknowledgments}

Thanks to the creator of heaven and earth, our God and also the Mapua University.

\section{REFERENCES}

[1] Akshay Dashore, "Delays in Construction Projects, Its Types, Effects and Management”, The Construction Building Ideas, https://theconstructor.org/construction/delays-construction-p rojects (accessed Jan 4, 2021).

[2] Ali, A., \& Kamaruzzaman,” S. COST PERFORMANCE FOR BUILDING CONSTRUCTION PROJECTS IN KLANG VALLEY”, Journal of Building Performance, Volume 1, Issue 1, pp. 110 -118, 2010. ISSN: 2180-2106.

[3] Sweis, G. J., Sweis, R., Rumman, M. A., Hussein, R. A., \& Dahiyat, S. E. Cost Overruns in Public Construction Projects: The Case of Jordan. Journal of American Science, pp. 134-141, 2013. DOI: 10.7537 ISSN: 1545-1003

[4] Gould, F. E., "Managing the construction process: Estimating, scheduling, and project control” Upper Saddle River, NJ: Prentice Hall, 2002.

[5] Syed Mohammad, Ather Nimalathasan Balasundaram, "Factor Analysis: Nature, Mechanism and Uses in Social and Management Science Research”, Journal of Cost and Management Accountant, Bangladesh. 2009, XXXVII (2):15-25.

[6] Yaw Frimpong, Jacob Oluwoye, Lynn Crawford, “Causes of delay and cost overruns in construction of groundwater projects in a developing countries; Ghana as a case study", International Journal of Project Management 21, pp 321-326, 2003. DOI: 10.1016/S0263-7863(02)00055-8

[7] Abdulelah Aljohani, Dominic Ahiaga-Dagbui, David Moore, "Construction Projects Cost Overrun: What Does the Literature Tell Us?”, International Journal of Innovation, Management and Technology, Vol. 8, No. 2, pp. 137-143, April 2017. DOI: 10.18178/ijimt.2017.8.2.717

[8] Kouskili, P.A. and Kartan, N., "Impact of construction materials on project time and cost in Kuwait", Journal of Construction and Architectural Management, Vol. 11, No. 2, pp 126-132, 2004. DOI:10.1108/09699980410527867

[9] Iyer, K.C., Chaphalkar, N.B. and Joshi, G.A., "Understanding time delay disputes in construction contracts.” International Journal of Project Management, Vol. 26, No.2, pp 174-184, 2007.

DOI:10.1016/j.ijproman.2007.05.002

[10]El-Razek, M.E.A., Bassoioni, H.A and Mobarak, A.M., "Causes of delay in building construction projects in Egypt", Journal of Construction Engineering and Management, Volume 134, Issue11, pp 831-841, 2008. DOI:10.1061/(asce)0733-9364

[11] Larsen, J. K., Shen, G. Q., Lindhard, S. M., \& Bruno, T. D., "Factors Affecting Schedule Delay, Cost Overrun, and Quality Level in Public Construction Projects”, Journal of Management in Engineering, Volume 32, Issue 1, pp. 04015032, 2016.

DOI:10.1061/(asce)me.1943-5479.0000391

[12] Sadi A. Assaf, Sadiq Al-Hejji, "Causes of delay in large construction projects”, International Journal of Project Management, Volume 24, Issue 4, pp. 349-357, 2006. DOI: 10.1016/j.ijproman.2005.11.010

[13] Nashwan Al-Emad, Ismail Abdul Rahman, Sasitharan Nagapan and Yaser Gamil, "Ranking of Delay Factors for Makkah's Construction Industry”, MATEC Web Conf. International Symposium on Civil and Environmental Engineering 2016 (ISCEE 2016), Volume 103, 2017. DOI: https://doi.org/10.1051/matecconf/201710303001

[14] Tengan Callistus, Aigbavboa Clinton, "The Role of Monitoring and Evaluation in Construction Project Management”, Intelligent Human Systems Integration, pp. 571-582, 2018. DOI:10.1007/978-3-319-73888-8_89

[15] Sadi Assaf, Mohammad A. Hassanain, Abdullatif Abdallah, "Assessment of Deficiencies in Design Documents for Large Construction Projects", Journal of Performance of Constructed Facilities volume 31, issue 5, pp. 04017086, 2017. DOI:10.1061/(asce)cf.1943-5509.0001081

[16] T.Subramani, Sruthi, P. S., \& Kavitha, M. (2014). Causes of Cost Overrun In Construction. IOSR Journal of Engineering (IOSRJEN), volume 4, issue 6, pp. 01-07, 2014. DOI:10.9790/3021-04640107

[17] Larsen J.K., Shen G.Q.P., Lindhard S.M. and Brunoe T.D. "Factors Affecting Schedule Delay, Cost Overrun, and Quality Level in Public Construction Projects", Journal of Management in Engineering, Volume 32 Issue 1, 2015. DOI 10.1061/(ASCE)ME.1943-5479.0000391

[18] Ofir Agasi and team, “C\# (C-Sharp) Definition”, techopedia, 
https://www.techopedia.com/definition/26272/c-sharp\#. (accessed Feb 6, 2021)

[19] Sabah Alkass, Mark Mazerolle, Eladio Tribaldos, \& Frank Harris, "Computer aided construction delay analysis and claims preparation”, Construction Management for Economics, Vol. 13, pp. 335-352, Nov 1994, doi.org/10.1080/01446199500000038

[20] Jing Sun, "Research on Construction of Enterprise Informatization Based on Computer Application Technology", International Conference on Information Sciences, Machinery, Materials and Energy (ICISMME 2015), doi.org/10.2991/icismme-15.2015.425. 